\title{
Advancing Control for Shield Tunneling Machine by Backstepping Design with LuGre Friction Model
}

\author{
Haibo Xie, Zhibin Liu, and Huayong Yang \\ State Key Laboratory of Fluid Power Transmission and Control, Hangzhou 310027, China \\ Correspondence should be addressed to Zhibin Liu; lbaddie@zju.edu.cn
}

Received 25 February 2014; Accepted 10 April 2014; Published 18 May 2014

Academic Editor: Weichao Sun

Copyright (c) 2014 Haibo Xie et al. This is an open access article distributed under the Creative Commons Attribution License, which permits unrestricted use, distribution, and reproduction in any medium, provided the original work is properly cited.

\begin{abstract}
Shield tunneling machine is widely applied for underground tunnel construction. The shield machine is a complex machine with large momentum and ultralow advancing speed. The working condition underground is rather complicated and unpredictable, and brings big trouble in controlling the advancing speed. This paper focused on the advancing motion control on desired tunnel axis. A three-state dynamic model was established with considering unknown front face earth pressure force and unknown friction force. LuGre friction model was introduced to describe the friction force. Backstepping design was then proposed to make tracking error converge to zero. To have a comparison study, controller without LuGre model was designed. Tracking simulations of speed regulations and simulations when front face earth pressure changed were carried out to show the transient performances of the proposed controller. The results indicated that the controller had good tracking performance even under changing geological conditions. Experiments of speed regulations were carried out to have validations of the controllers.
\end{abstract}

\section{Introduction}

Shield tunneling has become the most popular solution for underground tunnel construction, and shield tunneling machine is the most important machine in the shield tunneling construction. After geological survey is done, an excavation plan is proposed according to the survey. Underground environment is rather complicated, and it is impossible to explore everything along the designed excavation axis. The main working parameters of shield tunneling machine are the thrust force, advancing speed, and cutter head rotational speed. In reality, however, the operator is not only detecting these parameters, but also the posture of the machine, foam injection control, and rotational speed control of screw conveyor. To solve this problem, a control method is proposed to make the advance displacement $x$ converge to the designed displacement $x_{d}$. As a result, machine operator can focus on others like earth balance control and posture control.

As shown in Figure 1, the shield tunneling machine is surrounded by soil when it is constructing. The three primary forces along the excavation axis are the earth pressure force on the cutter head, the friction force on the machine's cylinder lining, and the thrust force generated by the hydraulic thrust cylinders. The figure shows a 16-thrust-cylinder system. Such system is usually arranged into a 4-group distribution with a proportion of $3: 4: 4: 5$, so as to reduce the components in hydraulic system.

Figure 2 shows a typical hydraulic thrust system circuit on shield tunneling machine. As mentioned before, there are 4 groups of thrust cylinders, and so 4 control sets are required. Unit 1 is a pressure compensation pump which is regulated by unit 3 , which is a pilot proportional pressure relief valve. Unit 2 is a safety pressure relief valve. The proportional flow control valve, unit 4 , is used for pressure compensation. Valve 6, proportional pressure relief valve, is applied for pressure regulation. The on/off control valve 5 is for fast extension/retraction motion when bypassing the valve 4. Directional control valve 7 is used for individual control of the extension/stop/retraction motion of cylinder 8 . When the machine is excavating, pump pressure is set to a high value which is enough for all the cylinder pressure regulation. Valve 5 is off and valve 4 is set to a certain value that provides large enough flow rate for the system. The operator can control the thrust force by adjusting the output pressure of valve 6 . 


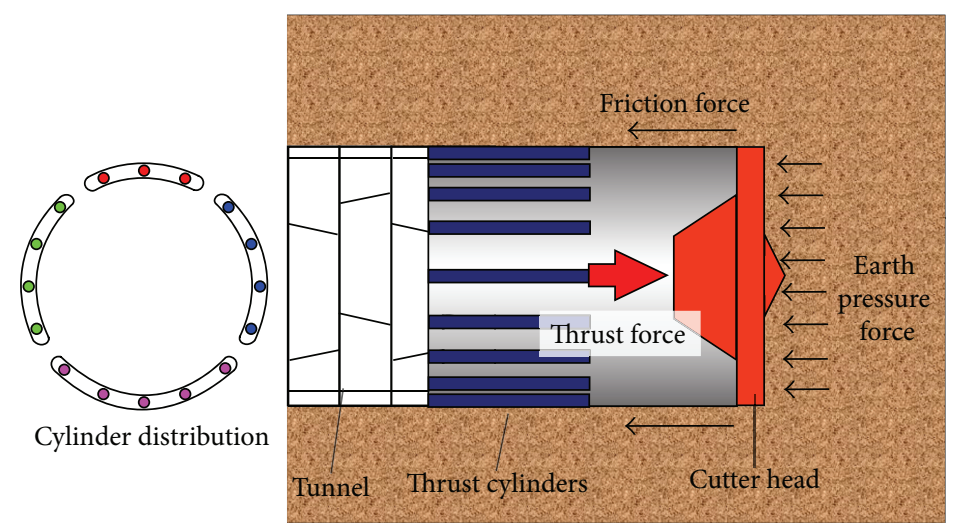

FIGURE 1: Cross section of a shield tunneling machine.

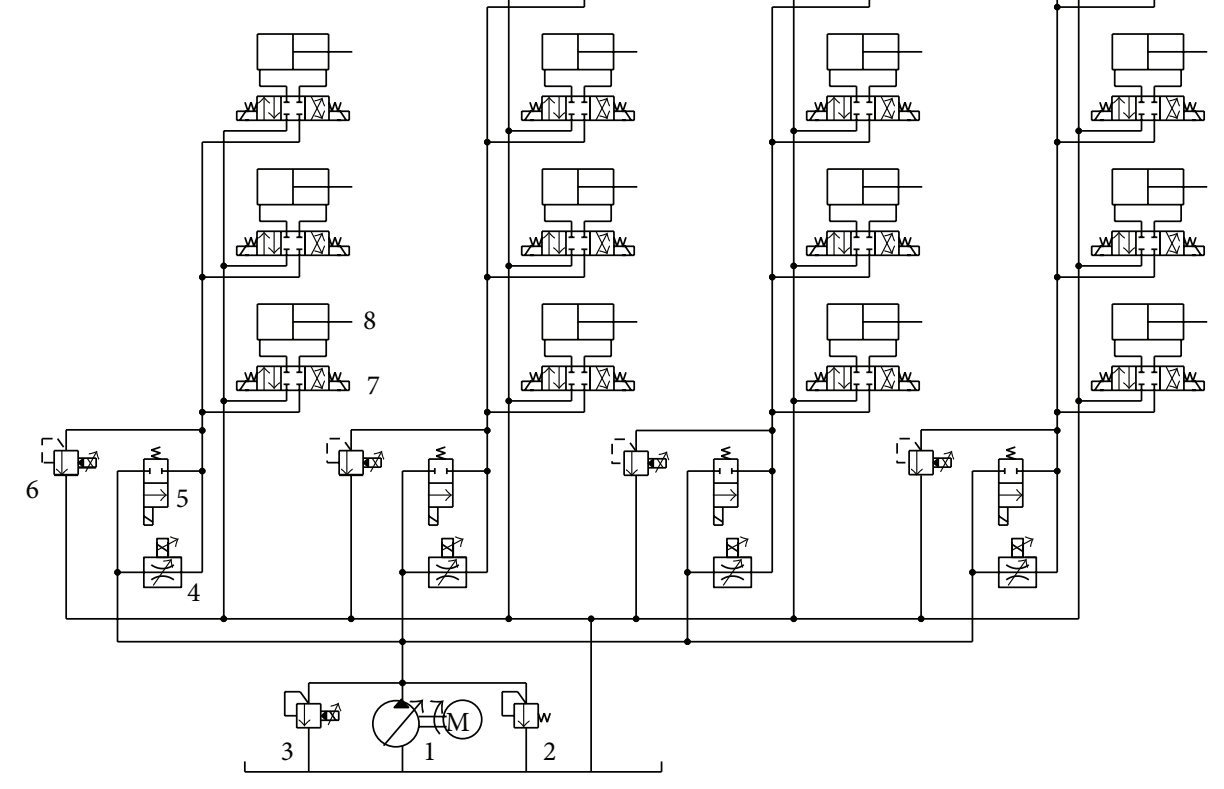
(1) Hydraulic pump
(5) On/off valve
(2) Pressure relief valve
(6) Proportional pressure relief valve
(3) Proportional pressure relief valve
(7) Directional control valve
(4) Flow rate control valve
(8) Hydraulic cylinder

FIgURE 2: Typical hydraulic thrust system on shield tunneling machine.

Some previous works about tunnel excavation were done. Sugimoto et al. studied the shield machine excavation behaviors. They modeled the excavation progress and made some comparisons with simulations and site observed data [1-3]. Farrokh et al. studied the inter relationship between different working parameters based on different feeding speeds [4].
Ramoni and Anagnostou's work was similar to Farrokh et al., but the working conditions he studied were not unified [5]. And some works about motion control were done. Manabe et al. studied the excavation direction control by using Kalman filter and LQR [6]. Yue et al. applied sliding mode control for shield machine coordinated control and some 
simulation works were presented [7]. Yang et al. introduced a conventional electrohydraulic control system on the machine [8].

In this paper, advancing tracking control is concerned by using the famous LuGre friction model in modeling the friction force. Shield machine advances with an ultralow speed. Speed change will make friction force change, which is known as the Stribeck effect. In shield tunneling application, friction force is approximately half of the thrust force, and thus such friction force change will bring influences on the advancing motion. The conventional control on the machine is manual control. A few reports of automatic control on shield machine are revealed, but the great influence of friction force was usually neglected. The LuGre friction model was first proposed in de Wit et al.s paper in 1995 [9], and some application reviews were reported by the same authors [10]. Application on AC servomotor controller design was presented by Tan et al., and load uncertainty was considered in their works [11]. Piatkowski analyzed two dynamic friction models, Dahl and LuGre, and reported some comparison studies and the properties [12]. Freidovich et al. applied LuGre model friction compensation on controlling a DC motor-rigid arm system [13]. In addition, to handle nonlinear friction effects in hydraulic servo systems, Yao et al. proposed a force controller of hydraulic system with considering model-based friction compensation via LuGre model [14]. The authors in [15] also developed an advanced robust controller with parameter adaptation to handle unknown frictions and other modeling uncertainties. An evident advantage of this controller is that it can avoid complicated friction identification process and thus is very suitable for physical applications. Excellent theoretical and experimental results were achieved by the proposed advanced controller in [15].

\section{Modeling}

First some notations are defined in Table 1.

Assumption 1. In the hydraulic thrust system, the thrust force is bounded. Compared with the whole machine dynamics, the hydraulic dynamics can be ignored.

Assumption 2. Earth pressure on the cutter head and friction force on the lining are unknown.

Assumption 3. The stratum is unified on the radial direction, but changing along the advancing axis.

Newton's second law was applied to the shield machine dynamics on the excavation axis. Consider the following:

$$
m \ddot{x}=u-f-F .
$$

The LuGre model was proposed by Astrom in 1995, and the dynamic model is expressed as follows:

$$
\begin{gathered}
f=\sigma_{0} z+\sigma_{1} \frac{d z}{d t}+\sigma_{2} v \\
\frac{d z}{d t}=v-\frac{|v|}{g(v)} z .
\end{gathered}
$$

\begin{tabular}{|c|c|}
\hline Symbols & Physical quantities \\
\hline$m$ & Mass of shield machine \\
\hline$f$ & Lumped force of friction force and viscous force \\
\hline$F$ & Earth pressure force exerted on cutter head \\
\hline$z$ & Average deflection of the bristles \\
\hline$v$ & Relative velocity between two friction surfaces \\
\hline$\sigma_{0}$ & Stiffness of the bristles \\
\hline$\sigma_{1}$ & Damping coefficient \\
\hline$\sigma_{2}$ & Viscous coefficient \\
\hline$F_{C}$ & Coulomb friction force \\
\hline$F_{S}$ & Stiction force \\
\hline$v_{s}$ & Stribeck velocity \\
\hline$x_{1}$ & Displacement of shield machine \\
\hline$x_{2}$ & Velocity of shield machine \\
\hline$x_{1 d}$ & Desired displacement \\
\hline$x_{2 d}$ & Desired velocity \\
\hline$e_{1}$ & Tracking error of displacement \\
\hline$e_{2}$ & Tracking error of velocity \\
\hline$V_{i}$ & Lyapunov funcitons \\
\hline : & First order derivative \\
\hline$\ddot{\bullet}$ & second order derivative \\
\hline$\hat{\bullet}$ & Estimated value \\
\hline • & $\widehat{\bullet}-\bullet$, error between estimated value and true value \\
\hline$k_{i}$ & Feedback gain \\
\hline$\lambda_{i}$ & Adaptation gain \\
\hline
\end{tabular}

TABLE 1: Notations in modeling.

The function $g(v)$ is defined the same way as that in Astrom's paper, which is as follows:

$$
\sigma_{0} g(v)=F_{C}+\left(F_{S}-F_{C}\right) e^{-\left(v / v_{s}\right)^{2}}
$$

Let $x_{1}=x, x_{2}=v, J_{1}\left(x_{2}\right)=\sigma_{0}-\sigma_{1}\left(\left|x_{2}\right| / g\left(x_{2}\right)\right), J_{2}=\sigma_{1}+\sigma_{2}$. And the dynamic model can be derived as

$$
\begin{aligned}
& \dot{x}_{1}=x_{2} \\
& \dot{x}_{2}=\frac{1}{m}\left(u-F-J_{1}\left(x_{2}\right) z-J_{2} x_{2}\right) \\
& \dot{z}=x_{2}-\frac{\left|x_{2}\right|}{g\left(x_{2}\right)} z .
\end{aligned}
$$

\section{Controller Design}

\subsection{Backstepping Design with LuGre Model}

Step 1. Let $e_{1}=x_{1}-x_{1 d}, e_{2}=x_{2}-x_{2 d}$. The goal is to design $x_{2 d}$ to make $e_{1}$ asymptotically stable. Here, $x_{1 d}$ should be second order differentiable. The Lyapunov function is chosen as

$$
V_{1}\left(e_{1}\right)=\frac{1}{2} e_{1}^{2}
$$


And its derivative is

$$
\dot{V}_{1}\left(e_{1}\right)=\dot{e}_{1} e_{1}=\left(x_{2}-\dot{x}_{1 d}\right) e_{1}
$$

If $x_{2}$ can be the same as $x_{2 d}=\dot{x}_{1 d}-k_{1} e_{1}$, then $\dot{V}_{1}\left(e_{1}\right)=$ $-k_{1} e_{1}^{2} \leq 0$. By applying the LaSalle's invariance principle, $e_{1}$ converges to zero. So the desired value of $x_{2}$ is $\dot{x}_{1 d}-k_{1} e_{1}$.

Step 2. Assume that $F, J_{1}$, and $J_{2}$ are known; design a control input $u$ so as to make $e_{1}$ and $e_{2}$ to achieve asymptotic stability.

The Lyapunov function is chosen as

$$
\begin{aligned}
V_{2}\left(e_{1}, e_{2}\right)= & \frac{1}{2} e_{1}^{2}+\frac{1}{2} e_{2}^{2} \\
\dot{V}_{1}\left(e_{1}, e_{2}\right)= & \dot{e}_{1} e_{1}+\dot{e}_{2} e_{2} \\
= & \left(x_{2 d}+e_{2}-\dot{x}_{1 d}\right) e_{1} \\
& +\left[\frac{1}{m}\left(u-F-J_{1}\left(x_{2}\right) z-J_{2} x_{2}\right)\right. \\
= & \left.\left.\quad-x_{2 d}-\dot{x}_{1 d}\right) e_{1} \dot{e}_{1}\right] e_{2} \\
& +\left[\frac{1}{m}\left(u-F-J_{1}\left(x_{2}\right) z-J_{2} x_{2}\right)\right. \\
& \left.\quad-\ddot{x}_{1 d}+k_{1} \dot{e}_{1}+e_{1}\right] e_{2} .
\end{aligned}
$$

If the control input $u$ is chosen as

$$
u=m\left(\ddot{x}_{1 d}-k_{1} \dot{e}_{1}-e_{1}-k_{2} e_{2}\right)+F+J_{1}\left(x_{2}\right) z+J_{2} x_{2},
$$

the derivative of $V_{2}$ becomes

$$
\dot{V}_{2}\left(e_{1}, e_{2}\right)=-k_{1} e_{1}^{2}-k_{2} e_{2}^{2} \leq 0 .
$$

Again, by applying LaSalle's invariance principle, $e_{1}$ and $e_{2}$ converge to zero.

Step 3. Because the true values of $F, J_{1}, J_{2}$, and $z$ are unknown, their estimated values are used to manipulate the controller. Hence, the control input is

$$
u=m\left(\ddot{x}_{1 d}-k_{1} \dot{e}_{1}-e_{1}-k_{2} e_{2}\right)+\widehat{F}+\widehat{J}_{1}\left(x_{2}\right) \widehat{z}+\widehat{J}_{2} x_{2} .
$$

A state observer is applied to estimate the value of $z$, which has the following form:

$$
\dot{\vec{z}}=x_{2}-\frac{\left|x_{2}\right|}{g\left(x_{2}\right)} \widehat{z}+h \text {. }
$$

The item $h$ will be determined later to stabilize the system. Hence the error dynamic of $z$ is

$$
\dot{\tilde{z}}=-\frac{\left|x_{2}\right|}{g\left(x_{2}\right)} \widetilde{z}+h .
$$

The $V_{2}$ derivative becomes

$$
\begin{aligned}
\dot{V}_{2}\left(e_{1}, e_{2}\right)= & -k_{1} e_{1}^{2}-k_{2} e_{2}^{2} \\
& +\frac{1}{m}\left(\widetilde{F}+\widetilde{J}_{2} x_{2}+\widehat{J}_{1}\left(x_{2}\right) \widehat{z}-J_{1}\left(x_{2}\right) z\right) e_{2} \\
= & -k_{1} e_{1}^{2}-k_{2} e_{2}^{2} \\
& +\frac{1}{m}\left(\widetilde{F}+\widetilde{J}_{2} x_{2}+\widehat{J}_{1} \widehat{z}-J_{1} \widehat{z}+J_{1} \widehat{z}-J_{1} z\right) e_{2} \\
= & -k_{1} e_{1}^{2}-k_{2} e_{2}^{2}+\frac{1}{m}\left(\widetilde{F}+\widetilde{J}_{2} x_{2}+\widetilde{J}_{1} \widehat{z}+J_{1} \widetilde{z}\right) e_{2} .
\end{aligned}
$$

Equation (13) is not seminegative. For the convergence, the Lyapunov function is augmented by adding $\widetilde{F}, \widetilde{J}_{1}, \widetilde{J}_{2}, \widetilde{z}$ as the variables. The new Lyapunov function is

$$
\begin{aligned}
V_{3}\left(e_{1}, e_{2}, \widetilde{F}, \widetilde{J}_{1}, \widetilde{J}_{2}, \widetilde{z}\right)= & \frac{1}{2}\left(e_{1}^{2}+e_{2}^{2}\right)+\frac{1}{2 \lambda_{1}} \widetilde{F}^{2} \\
& +\frac{1}{2 \lambda_{2}} \widetilde{J}_{1}^{2}+\frac{1}{2 \lambda_{3}} \widetilde{J}_{2}^{2}+\frac{J_{1}}{2 \lambda_{4}} \widetilde{z}^{2} .
\end{aligned}
$$

And its derivative is

$$
\begin{aligned}
V_{3}\left(e_{1}, e_{2}, \widetilde{F}, \widetilde{J}_{1}, \widetilde{J}_{2}, \widetilde{z}\right) \\
=-k_{1} e_{1}^{2}-k_{2} e_{2}^{2} \\
\quad+\frac{1}{m}\left(\widetilde{F}+\widetilde{J}_{1} \widehat{z}+\widetilde{J}_{2} x_{2}+J_{1} \widetilde{z}\right) e_{2} \\
\quad+\frac{1}{\lambda_{1}} \dot{\hat{F}} \cdot \widetilde{F}+\frac{1}{\lambda_{2}} \dot{\widehat{J}}_{1} \cdot \widetilde{J}_{1}+\frac{1}{\lambda_{3}} \dot{\widehat{J}}_{2} \cdot \widetilde{J}_{2}+\frac{J_{1}}{\lambda_{4}} \dot{\tilde{z}} \cdot \widetilde{z} .
\end{aligned}
$$

If we choose the adaptive control law as

$$
\begin{array}{ll}
\dot{\hat{F}}=-\frac{\lambda_{1}}{m} e_{2}, & \dot{\widehat{J}}_{1}=-\frac{\lambda_{2}}{m} \widehat{z} e_{2}, \\
\dot{\widehat{J}}_{2}=-\frac{\lambda_{3}}{m} x_{2} e_{2}, & h=-\frac{\lambda_{4}}{m} e_{2},
\end{array}
$$

the derivative of $V_{3}$ becomes

$$
V_{3}\left(e_{1}, e_{2}, \widetilde{F}, \widetilde{J}_{1}, \widetilde{J}_{2}, \widetilde{z}\right)=-k_{1} e_{1}^{2}-k_{2} e_{2}^{2}-\frac{J_{1}}{\lambda_{4}} \cdot \frac{\left|x_{2}\right|}{g\left(x_{2}\right)} \widetilde{z}^{2} \leq 0 .
$$

Equation (17) means that $V_{3}$ is bounded. LaSalle's invariance principle cannot be applied here. A simple proof, as follows, will illustrate the $e_{1}$ converges to zero. Consider the integral

$$
\begin{aligned}
\int_{0}^{+\infty} & f\left(e_{1}, e_{2}, \widetilde{z}\right) d t \\
\quad= & \int_{0}^{+\infty}\left(k_{1} e_{1}^{2}+k_{2} e_{2}^{2}+\frac{J_{1}}{\lambda_{4}} \cdot \frac{\left|x_{2}\right|}{g\left(x_{2}\right)} \widetilde{z}^{2}\right) d t \\
= & -\int_{0}^{+\infty} \dot{V}_{3} d t=V_{3}(0)-V_{3}(+\infty) .
\end{aligned}
$$

Because $V_{3}(t)$ is bounded, $\int_{0}^{+\infty} f\left(e_{1}, e_{2}, \widetilde{z}\right) d t$ is bounded. 
Note that $f\left(e_{1}, e_{2}, \widetilde{z}\right)=k_{1} e_{1}^{2}+k_{2} e_{2}^{2}+\left(J_{1} / \lambda_{4}\right) \cdot\left(\left|x_{2}\right| / g\right.$ $\left.\left(x_{2}\right)\right) \widetilde{z}^{2} \geq 0, \int_{0}^{+\infty} f\left(e_{1}, e_{2}, \widetilde{z}\right) d t$ is a nondecreasing function, and $\int_{0}^{+\infty} f\left(e_{1}, e_{2}, \widetilde{z}\right) d t$ converges to a certain bounded value. Note that $f\left(e_{1}, e_{2}, \tilde{z}\right)$ is uniformly continuous. By applying Babalat's lemma, $f\left(e_{1}, e_{2}, \widetilde{z}\right)$ converges to zero, which means that $e_{1} \rightarrow 0, e_{2} \rightarrow 0, \widetilde{z} \rightarrow 0$.

Thus, the proposed controller is the control output (10) and adaptation law (16).

3.2. Controller without LuGre Model. To have a comparison, a brief introduction of ordinary backstepping design without LuGre model is carried out.

The model, different from (4), has become

$$
\begin{aligned}
& \dot{x}_{1}=x_{2} \\
& \dot{x}_{2}=\frac{1}{m}\left(u-F_{2}-b x_{2}\right) .
\end{aligned}
$$

In a very similar process as above, the controller and adaptive laws can be derived as

$$
\begin{gathered}
u_{2}=m\left(\ddot{x}_{1 d}-k_{1} \dot{e}_{1}-e_{1}-k_{2} e_{2}\right)+\widehat{F}_{2}+\widehat{b} x_{2} \\
\dot{\widehat{F}}_{2}=-\frac{\lambda_{5}}{m} e_{2}, \quad \dot{\hat{b}}=-\frac{\lambda_{6}}{m} x_{2} e_{2},
\end{gathered}
$$

where $F_{2}$ is the lumped force of earth pressure force and friction force. The primary difference is that there are dynamic compensation item and bristles deformation observer in the controller with LuGre model but not in that without LuGre model.

3.3. Discussions on Controller Design. In the modeling, all the environment factors, like friction force and earth pressure force, are considered as unknown. The mass is assumed as known factor exactly in the process. This is reasonable because the masses of different parts of machine are known. And when these parts are assembled together, the machine mass is the total sum known.

For Assumption 1, the thrust force lower bound is zero, which means that the thrust pressure on hydraulic cylinder is zero. The upper bound is the lower value of the maximum thrust force and the maximum force to maintain earth pressure balance. The maximum thrust force is due to the maximum pressure in the hydraulic thrust system, usually regulated by a proportional pressure reducing valve or a proportional pressure relief valve. Earth pressure balance control requires the earth pressure on the cutting face is between the minimum active earth pressure and the maximum passive earth pressure. If earth pressure is lower than the minimum active earth pressure, this will lead to the stratum collapse, which may make unexpected settlement on the ground. On the other hand, if the pressure is higher than the maximum passive earth pressure, stratum ahead of the cutter head deforms, which might make a bump on the land surface. So it is important to make the thrust force in a bounded region. It is well known that there are model uncertainties and nonlinear factors in hydraulic system. The hydraulic dynamics are usually within $100 \mathrm{~ms}$, a single excavation motion is usually from 20 minutes to 40 minutes. To simply the controller design, the hydraulic dynamics is ignored. This research focuses on the whole machine motion control, so the high frequency hydraulic system dynamics are neglected. Some works on dealing with nonlinearities and modeling uncertainties in hydraulic servo system can be found in the paper [14-16].

For Assumption 3, different stratums on the cutting face will exert different loads on the cutter head, for example, hard rock on left side and clay on the right side of cutter head, which will exert a torque on the machine and effect on the posture of the shield machine. Posture control is important. In this paper, however, the axis motion is focused. It is expected to set up an automatic advancing controller for the excavation, in the hope to free the machine operator from the advancing motion control. Then the operator can focus on other works like earth pressure control and posture control. Under this assumption, we can only consider the advanced motion control along the designed axis.

\section{Simulation}

The simulation study was carried out by using commercial software MATLAB. First, two simulations were carried out. Both were with initial position errors of $10 \mathrm{~mm}$. The tracking starting points were set $10 \mathrm{~mm}$ ahead of the initial position of the shield tunneling machine. In simulation 1, tracking speed was regulated to a lower level after some time. In simulation 2, tracking speed was regulated to a higher level after some time. In most applications, shield machines are set to a certain constant advancing speed for some time intervals. Frequent changes of advancing speed might cause unnecessary disturbances to the cutting face and induce stratum deformation, which is unexpected. Regulation of advancing speed is carried out in order to achieve earth balance control, and it is usually accompanied with adjustments of other working parameters, such as rotational speed of cutter head and screw conveyor. Simulation parameters were set as Table 2 .

Figures 3 and 6 are tracking displacements. Figures 4 and 7 are tracking errors. Figures 5 and 8 are thrust forces. According to simulation results, both controllers had good tracking performances, and they both were able to make tracking errors converge to zero. At the beginning, both controllers could make tracking error convergences. Because the control outputs, which were in Figures 5 and 8, reached the maximum at the beginning, the errors with LuGre model converged faster. This convergence speed differences can be eliminated by adjusting the feedback gains and adaptation gains. When the desired speed was regulated to other values, then friction force was changing with the advancing speed change. Tracking errors of those with LuGre model had almost no influences, but errors without LuGre model varied significantly. Error was undershooting in simulation 1, and the other was overshooting in simulation 2. These errors were still converging because the adaptive control terms were still working. These results indicated the great benefits of 
TABle 2: Parameter setting in simulation.

\begin{tabular}{lcc}
\hline Parameter & Value & Unit \\
\hline$m$ & $3 \times 10^{5}$ & $\mathrm{Kg}$ \\
$k_{1}$ & 1.5 & 1 \\
$k_{2}$ & 3 & 1 \\
$F$ & $4 \times 10^{6}$ & $\mathrm{~N}$ \\
$F_{S}$ & $8 \times 10^{6}$ & $\mathrm{~N}$ \\
$F_{C}$ & $6 \times 10^{6}$ & $\mathrm{~N}$ \\
$v_{s}$ & 0.3 & $\mathrm{~mm} / \mathrm{s}$ \\
$\sigma_{0}$ & $5 \times 10^{7}$ & $\mathrm{~N} / \mathrm{m}$ \\
$\sigma_{1}$ & 200 & $\mathrm{Ns} / \mathrm{m}$ \\
$\sigma_{2}$ & $8 \times 10^{6}$ & $\mathrm{~N} /(\mathrm{mm} / \mathrm{s})$ \\
$b$ & $8 \times 10^{6}$ & $\mathrm{~N} /(\mathrm{mm} / \mathrm{s})$ \\
$\lambda_{1}$ & 5000 & 1 \\
$\lambda_{2}$ & 5000 & 1 \\
$\lambda_{3}$ & 5000 & 1 \\
$\lambda_{4}$ & 200 & 1 \\
$\lambda_{5}$ & 5000 & 1 \\
$\lambda_{6}$ & 5000 & 1 \\
$J_{10}$ & $4 \times 10^{7}$ & $\mathrm{~N} / \mathrm{m}$ \\
$J_{20}$ & $6 \times 10^{6}$ & $\mathrm{~N} /(\mathrm{mm} / \mathrm{s})$ \\
$F_{0}$ & $4.5 \times 10^{6}$ & $\mathrm{~N}$ \\
\hline
\end{tabular}

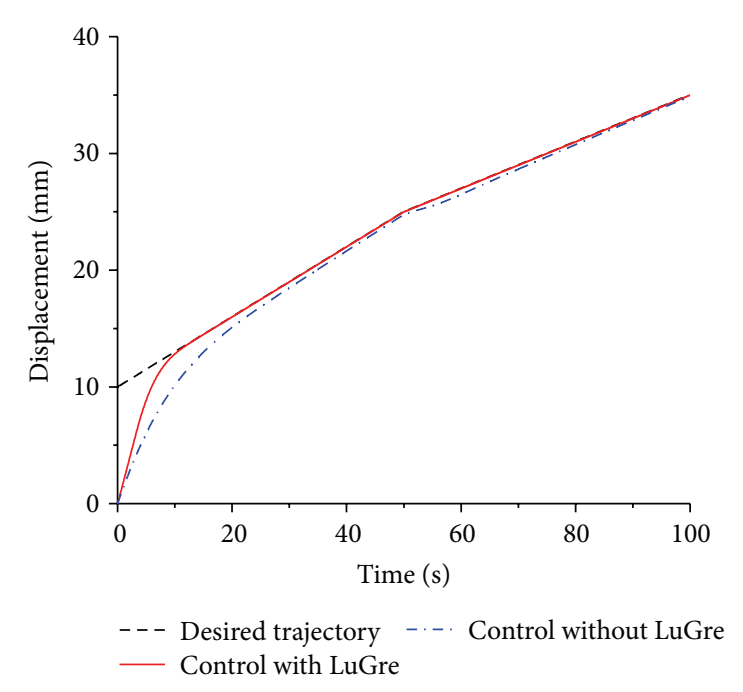

FIGURE 3: Displacement in simulation 1.

considering the LuGre model. Then look into the thrust forces of both controllers. The thrust force changes in simulation 1 were not significant, but the changes were great in simulation 2. Thrust forces were over compensated without LuGre model, which would bring more disturbances to stratum. And such disturbances were unexpected.

The former two simulations were trajectory tracking under constant environment factors. Underground environments are rather complicated, and thus geological conditions should be considered during the excavation process. Thanks to the adaptation law, slow changes of environment factor can be handled without a significantly bad effect on tracking

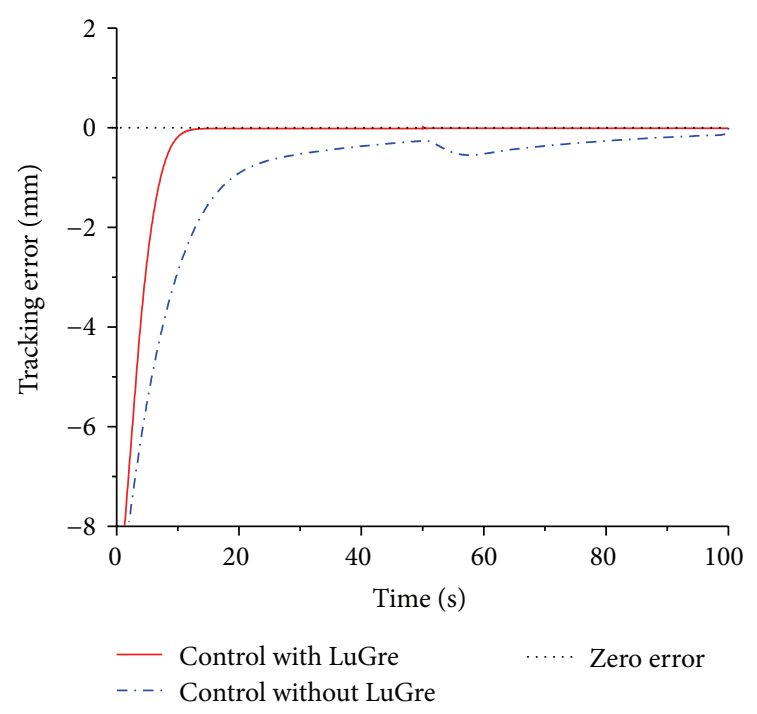

FIgURE 4: Tracking error in simulation 1.

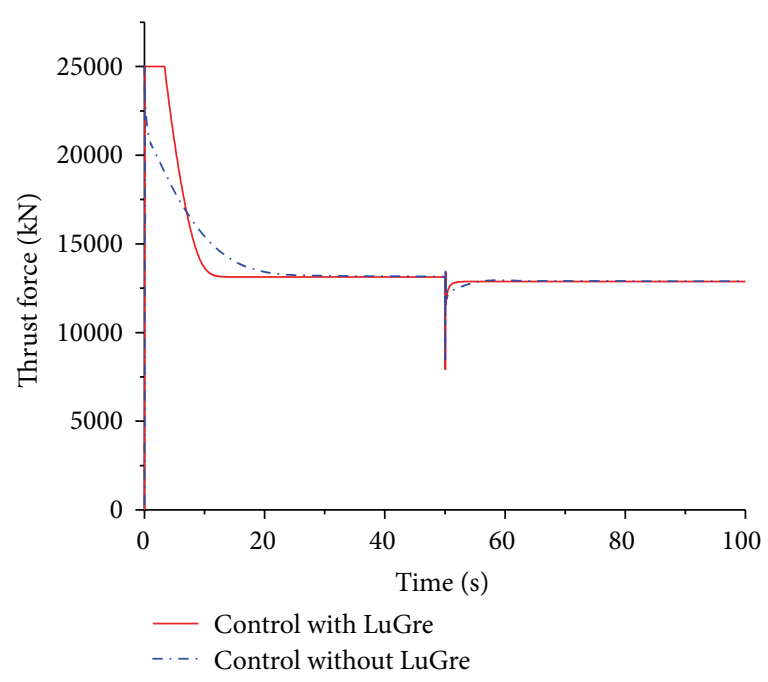

FIGURE 5: Thrust force in simulation 1.

control. To study the transient responses of the controllers, a sudden earth pressure increase was set at $40 \mathrm{~mm}$ of the trajectory. Simulation 3 was set to excavate on a constant advancing speed. The earth pressure force on the cutter head was $4 \times 10^{6} \mathrm{~N}$ and increased to $5 \times 10^{6} \mathrm{~N}$ suddenly at $40 \mathrm{~mm}$. Through the simulation results, controller with LuGre model had little effect on tracking performance. Controller without LuGre model had some transient tracking error at the changing point. Both controllers were able to track the trajectory asymptotically. The simulation 3 shows good performances of the controllers under changing geological conditions (see Figures 9, 10, and 11). 


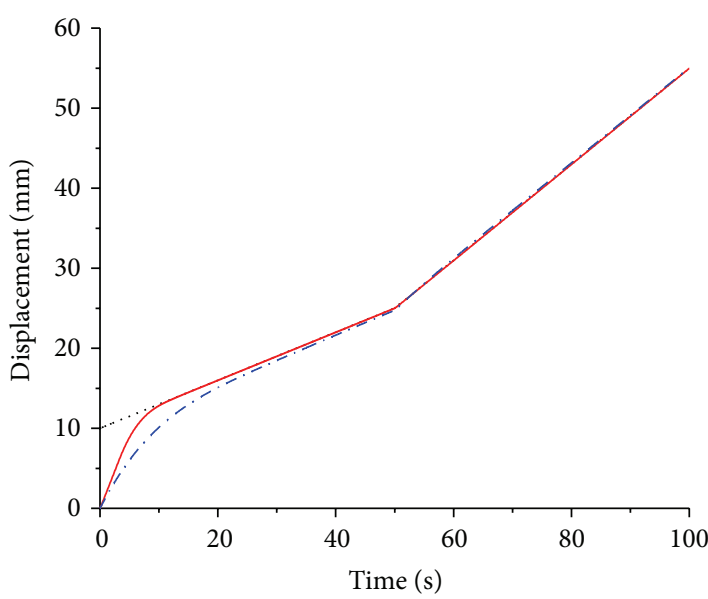

Desired trajectory _... Control without LuGre _ Control with LuGre

FIGURE 6: Displacement in simulation 2.

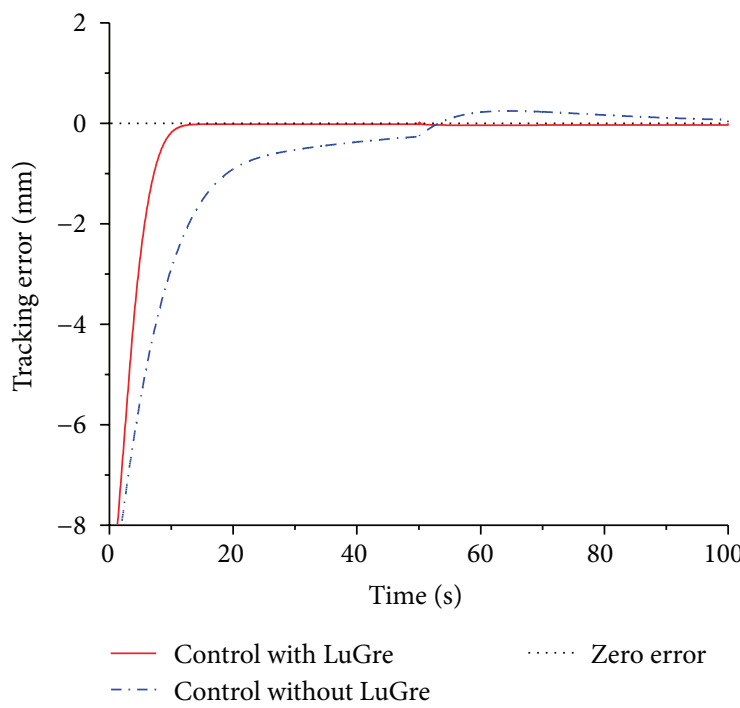

FIGURE 7: Tracking error in simulation 2.

\section{Experiments}

Two experiments were done on a laboratory scale test rig. The test rig is presented in Figure 12, and hydraulic schematic of the test rig is shown in Figure 13.

In Figure 13, cylinders 7 were the thrust cylinders and cylinders 9 were load simulation cylinders. And pressure gauges are installed, with a range of $0-40 \mathrm{MPa}$. The piston diameter was $180 \mathrm{~mm}$. Displacement of cylinders was measured by an encoder with resolution of $0.005 \mathrm{~mm}$. Pump 1 provided high pressure oil for experiments. The proportional flow control valves were HAWE type SHE 2-3, and the proportional pressure relief valves were HAWE type PMVP $5-44$. Valves 2 and 12 were set to the maximum, and valve 3 was the control input. Valve 13 was the load simulation input, and the loading was set as load model in paper [1]. Pump

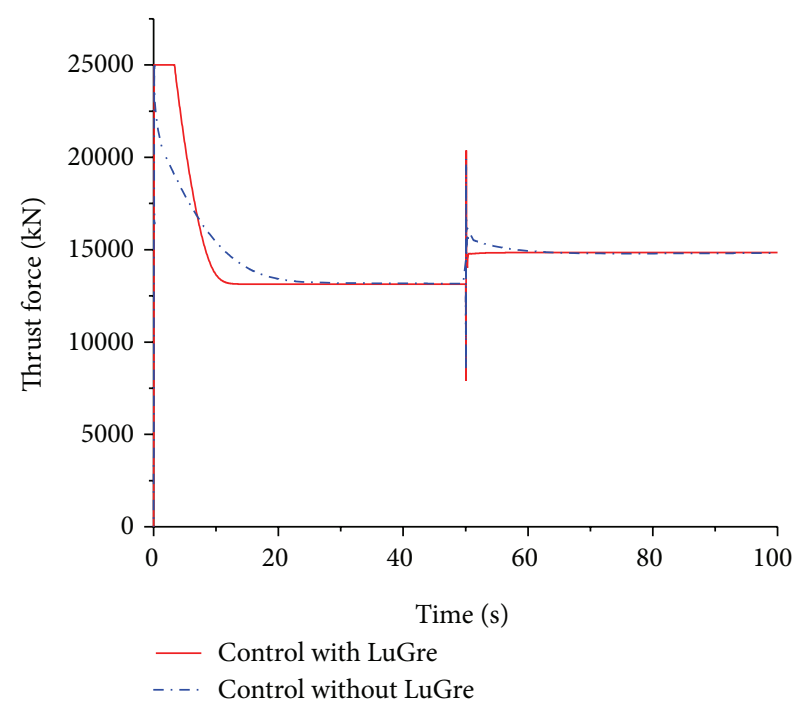

FIgURE 8: Thrust force in simulation 2.

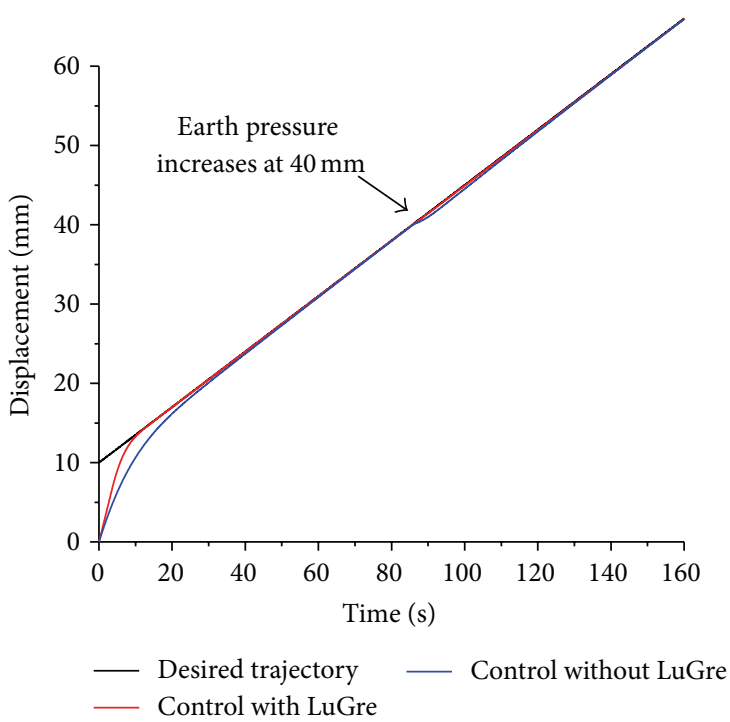

FIgURE 9: Displacement in simulation 3.

11 was a low pressure pump preventing cavitation when load cylinders were extending.

Experiment 1 was set as speed downregulation with an initial tracking error about $5.5 \mathrm{~mm}$ (see Figure 14). The desired trajectory was starting at $205 \mathrm{~mm}$ with speed of $1 \mathrm{~mm} / \mathrm{s}$ then was adjusted to $0.33 \mathrm{~mm} / \mathrm{s}$ at $30 \mathrm{~s}$ when reaching $235 \mathrm{~mm}$. Experiment 2 was set as speed upregulation with an initial tracking error about $4.5 \mathrm{~mm}$ (see Figure 15). The corresponding desired trajectory was starting at $205 \mathrm{~mm}$ with speed of $0.5 \mathrm{~mm} / \mathrm{s}$ and was adjusted to $1 \mathrm{~mm} / \mathrm{s}$ at $30 \mathrm{~s}$ when reaching $220 \mathrm{~mm}$. The mass was set as $970 \mathrm{~kg}$, and the adaptation gain was set as 1000 . $J_{1}$ was set to $4 \times 10^{6}$ because friction force on test rig was not as large as that on actual machine. Time interval was set to $80 \mathrm{~ms}$. The other parameters were set the same way as those in simulations. 


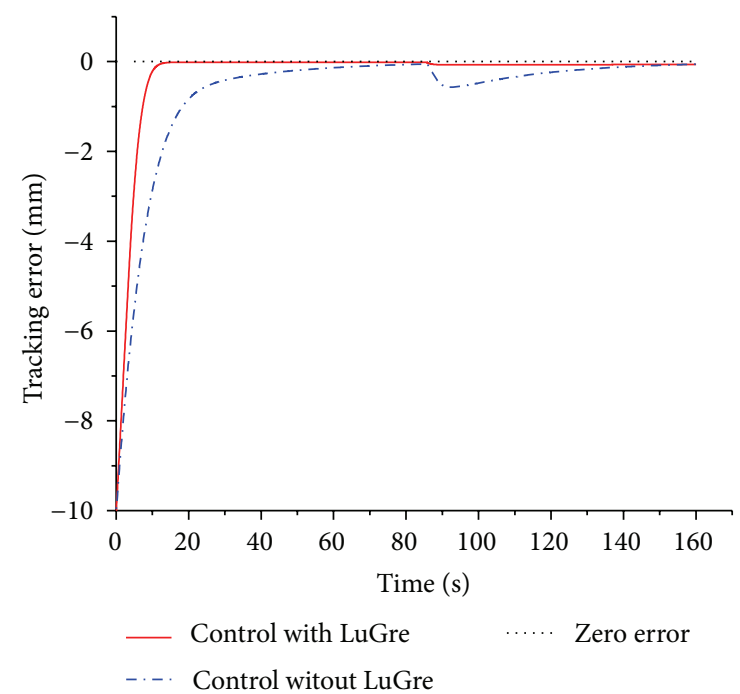

FIGURE 10: Tracking error in simulation 3.

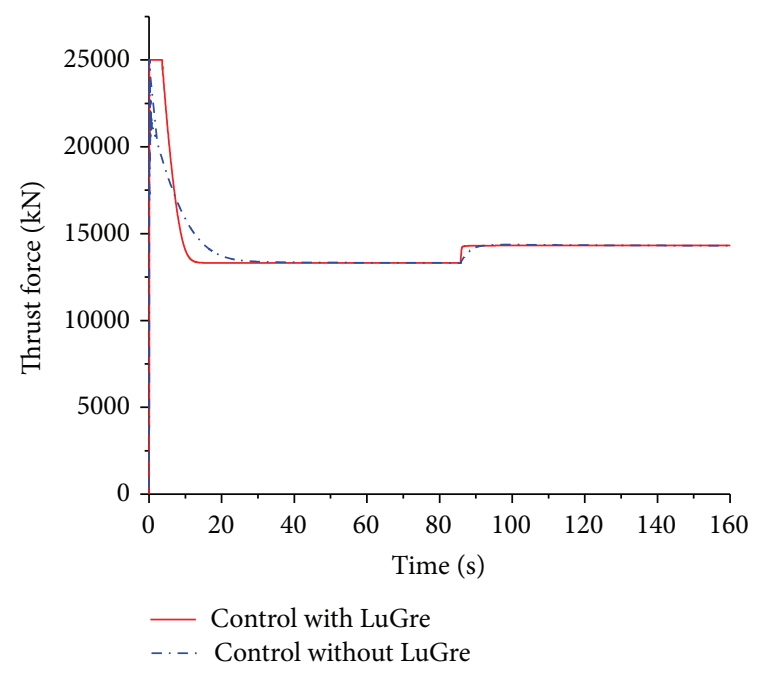

FIGURE 11: Thrust force in simulation 3.

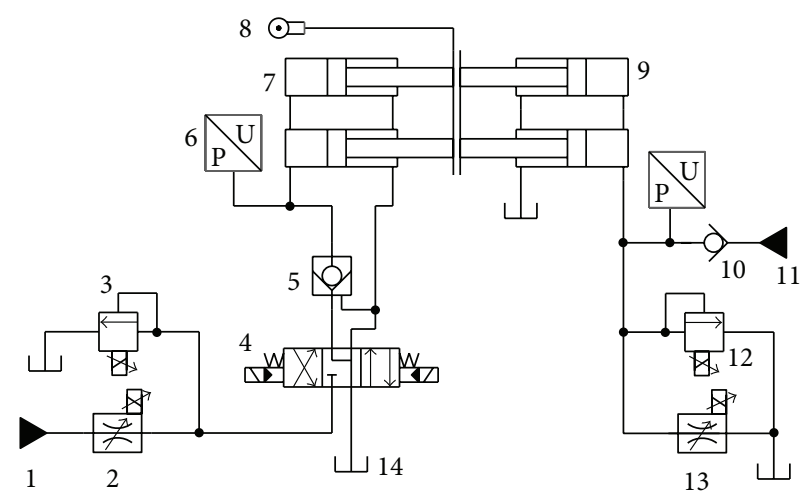

(1) Hydraulic pump

(7), (9) Hydraulic cylinder

(2), (13) Proportional flow control valve

(8) Displacement encoder

(3), (12) Proportional pressure relief valve

(10) Check valve

(4) Directional control valve

(11) Low pressure source

(5) Pilot controlled check valve

(14) Oil tank

(6) Pressure gauge

FIGURE 13: Hydraulic schematic of the test rig.

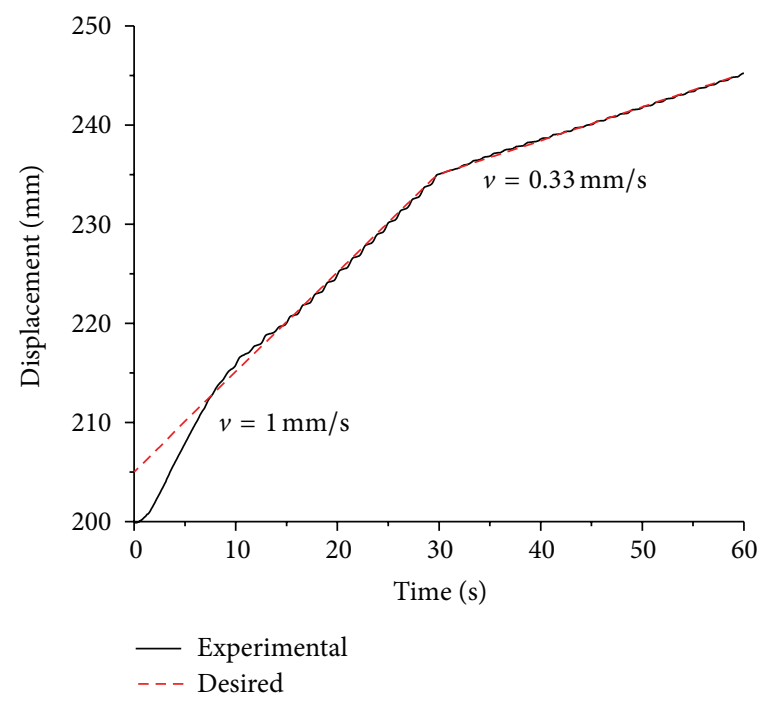

Figure 14: Displacement in experiment 1.

According to the experimental results, the machine tracked the desired trajectories. With a high speed at the beginning, both experiments took about $20 \mathrm{~s}$ to make tracking error less than $0.5 \mathrm{~mm}$ (see Figure 16). In site application, the tolerance tracking error is $2 \mathrm{~mm}$. And so such automatic tracking performances are capable in site application. When regulation changed at $30 \mathrm{~s}$, there was an influence in experiment 2 probably because it was speed upregulation and higher speed was more difficult to track. Some ripples occurred in tracking errors. There were some constraints in the experiments. A fast convergence was expected, and so high gain was applied, and it might cause the oscillation. Fuzzy gain scheduling may solve this problem, yet it is out 


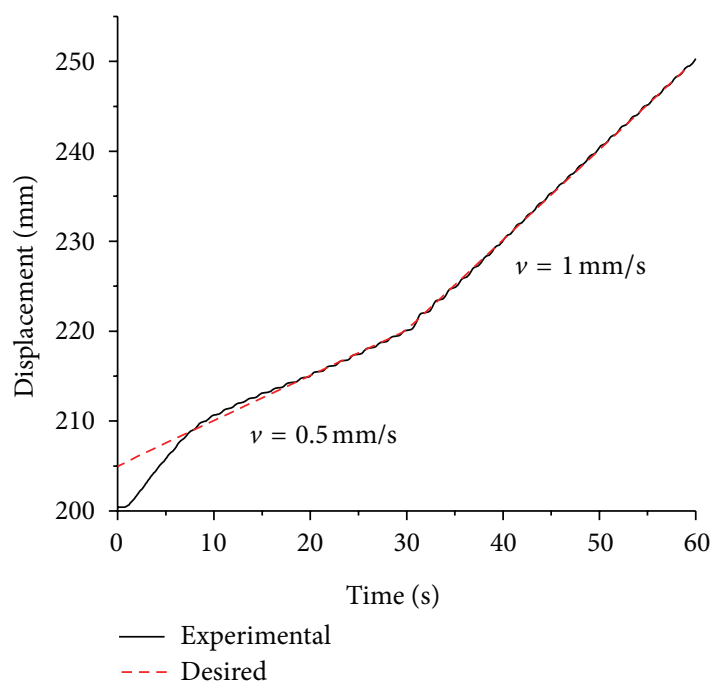

FIGURE 15: Displacement in experiment 2.

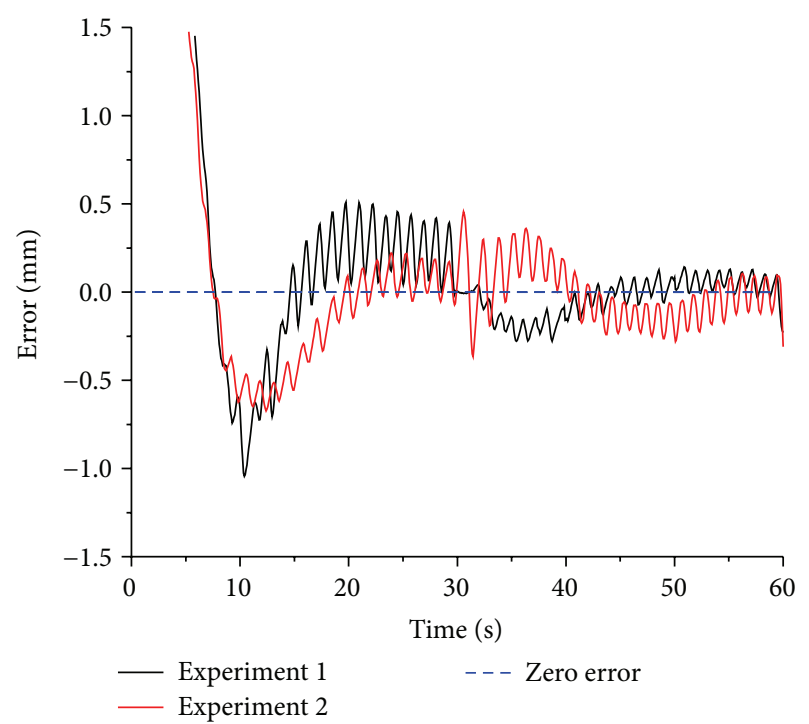

FIGURE 16: Tracking error.

of this paper's scope. The time interval is somehow long for real time control. But the speed was acquired by differential algorithm. Short time interval may induce large differential errors because of noise. Thus the setting time interval in the experiments might delay the real time control and cause the oscillation. Both tracking errors were less than $0.2 \mathrm{~mm}$ in the end. Error of experiment 1 was smaller. This might be because such fixed parameter controller was better for low speed tracking.

\section{Conclusions}

A three-state dynamic model for shield tunneling machine advancing motion was established. Two controllers, one was with LuGre model and the other was not, were proposed by using backstepping design. A simple proof showed that the controllers were able to make tracking errors converge to zero. Simulations of two common regulations of advancing control, speed-up, and speed-down regulations were carried out. The simulation results indicated that both controllers could make tracking errors converging. Looking into the details, controller with LuGre model had better tracking performance in dynamics progress. Simulations of front face earth pressure sudden change were carried out. The force on front face was set to increase by $25 \%$ suddenly. The results indicated controller with LuGre model had only a little influence on the force impact. The speed-up and speeddown regulations were also carried out in experimental study. The results show that the controller works well in actual apparatus.

\section{Conflict of Interests}

The authors declare that there is no conflict of interests regarding the publication of this paper.

\section{Acknowledgments}

This work was supported by The National Natural Science Funds of China (Grant no. 51275451), the National Basic Research Program of China (973 Program, Grant no. 2013CB035404), the Science Fund for Creative Research Groups of National Natural Science Foundation of China (Grant no. 51221004), and the National High Technology Research and Development Program of China 863 Program (Grant no. 2013AA040203).

\section{References}

[1] M. Sugimoto and A. Sramoon, "Theoretical model of shield behavior during excavation. I: theory," Journal of Geotechnical and Geoenvironmental Engineering, vol. 128, no. 2, pp. 138-155, 2002.

[2] A. Sramoon, M. Sugimoto, and K. Kayukawa, "Theoretical model of shield behavior during excavation. II: application," Journal of Geotechnical and Geoenvironmental Engineering, vol. 128, no. 2, pp. 156-165, 2002.

[3] M. Sugimoto, A. Sramoon, S. Konishi, and Y. Sato, "Simulation of shield tunneling behavior along a curved alignment in a multilayered ground," Journal of Geotechnical and Geoenvironmental Engineering, vol. 133, no. 6, pp. 684-694, 2007.

[4] E. Farrokh, J. Rostami, and C. Laughton, "Study of various models for estimation of penetration rate of hard rock TBMs," Tunnelling and Underground Space Technology, vol. 30, pp. 110123, 2012.

[5] M. Ramoni and G. Anagnostou, "Tunnel boring machines under squeezing conditions," Tunnelling and Underground Space Technology, vol. 25, no. 2, pp. 139-157, 2010.

[6] T. Manabe, M. Tanno, M. Matsumoto, and T. Yabuta, "Automatic direction control technique for microtunneling machine," in Proceedings of the 25th Annual Conference of the IEEE Industrial Electronics Society (IECON '99), pp. 1295-1300, December 1999.

[7] M. Yue, W. Sun, and P. Hu, "Dynamic coordinated control of attitude correction for the shield tunneling based on load observer," Automation in Construction, vol. 24, pp. 24-29, 2012. 
[8] H. Yang, H. Shi, G. Gong, and G. Hu, "Electro-hydraulic proportional control of thrust system for shield tunneling machine," Automation in Construction, vol. 18, no. 7, pp. 950956, 2009.

[9] C. C. de Wit, H. Olsson, K. J. Astrom, and P. Lischinsky, "A new model for control of systems with friction," IEEE Transactions on Automatic Control, vol. 40, no. 3, pp. 419-425, 1995.

[10] K. J. Åström and C. Canudas-de-Wit, "Revisiting the LuGre friction model," IEEE Control Systems Magazine, vol. 28, no. 6, pp. 101-114, 2008.

[11] Y. Tan, J. Chang, and H. Tan, "Adaptive backstepping control and friction compensation for AC servo with inertia and load uncertainties," IEEE Transactions on Industrial Electronics, vol. 50, no. 5, pp. 944-952, 2003.

[12] T. Piatkowski, "Dahl and LuGre dynamic friction modelsthe analysis of selected properties," Mechanism and Machine Theory, vol. 73, pp. 91-100, 2014.

[13] L. Freidovich, A. Robertsson, A. Shiriaev, and R. Johansson, "LuGre-model-based friction compensation," IEEE Transactions on Control Systems Technology, vol. 18, no. 1, pp. 194-200, 2010.

[14] J. Yao, Z. Jiao, and B. Yao, "Robust control for static loading of electro-hydraulic load simulator with friction compensation," Chinese Journal of Aeronautics, vol. 25, no. 6, pp. 954-962, 2012.

[15] J. Yao, Z. Jiao, D. Ma, and L. Yan, "High-accuracy tracking control of hydraulic rotary actuators with modelling uncertainties," IEEE/ASME Transactions on Mechatronics, vol. 19, no. 2, pp. 633-641, 2014.

[16] B. Yao, F. Bu, J. T. Reedy, and G. T. C. Chiu, "Adaptive robust motion control of single-rod hydraulic actuators: theory and experiments," IEEE/ASME Transactions on Mechatronics, vol. 5, no. 1, pp. 79-91, 2000. 


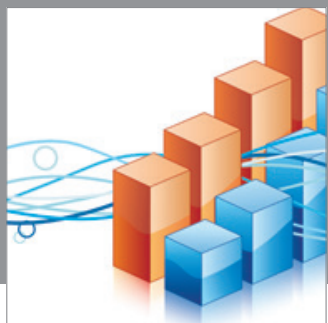

Advances in

Operations Research

mansans

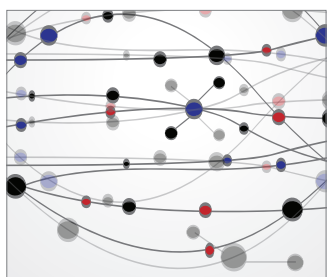

The Scientific World Journal
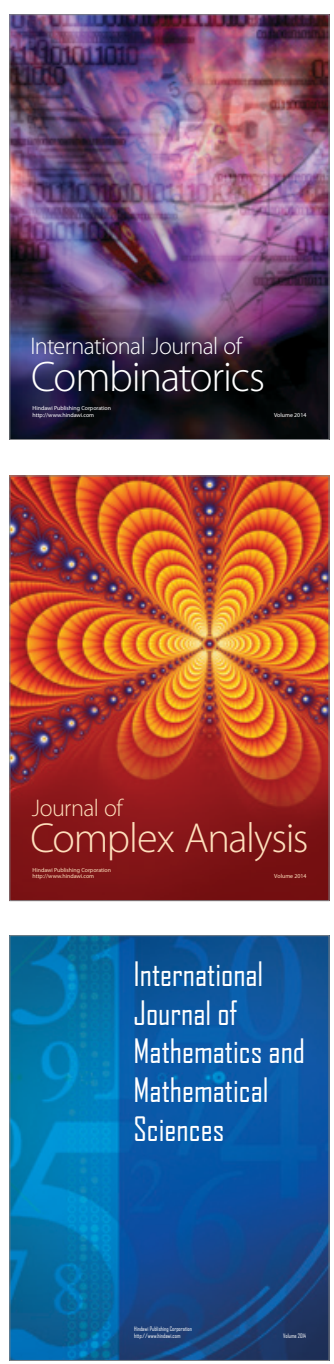
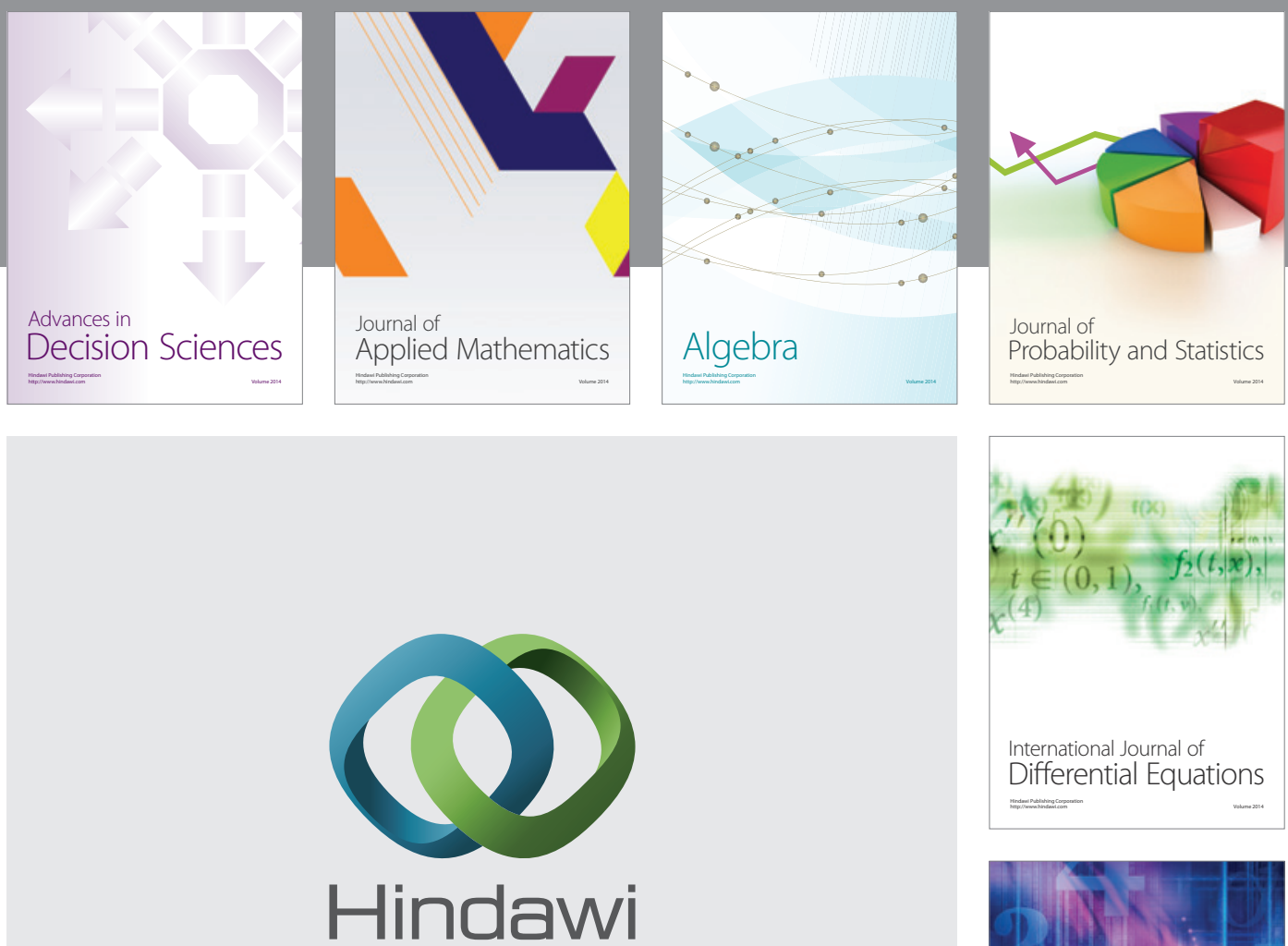

Submit your manuscripts at http://www.hindawi.com
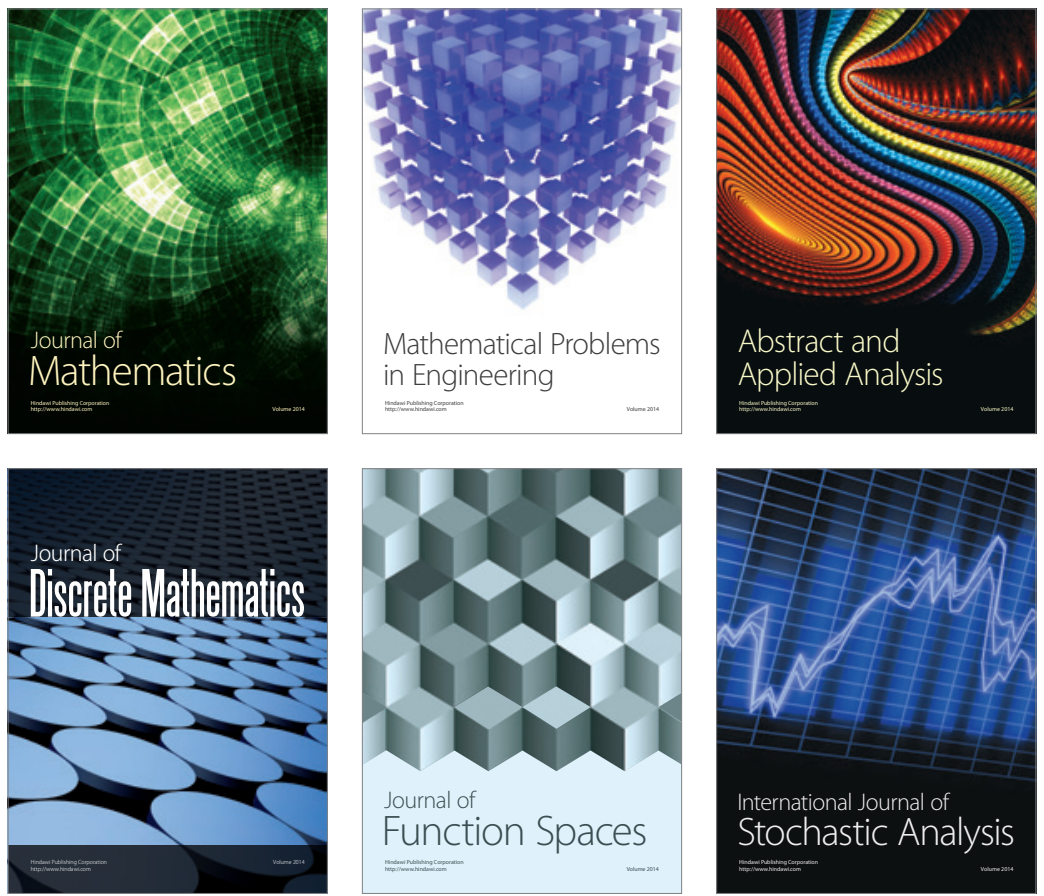

Journal of

Function Spaces

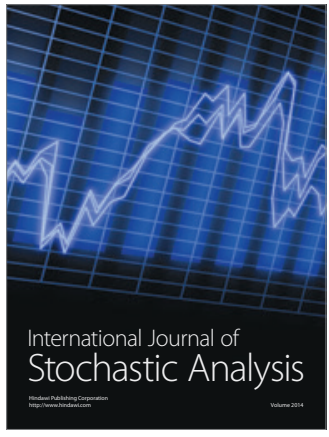

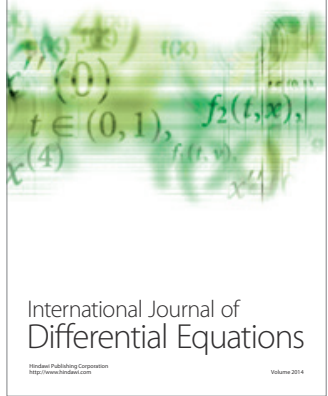
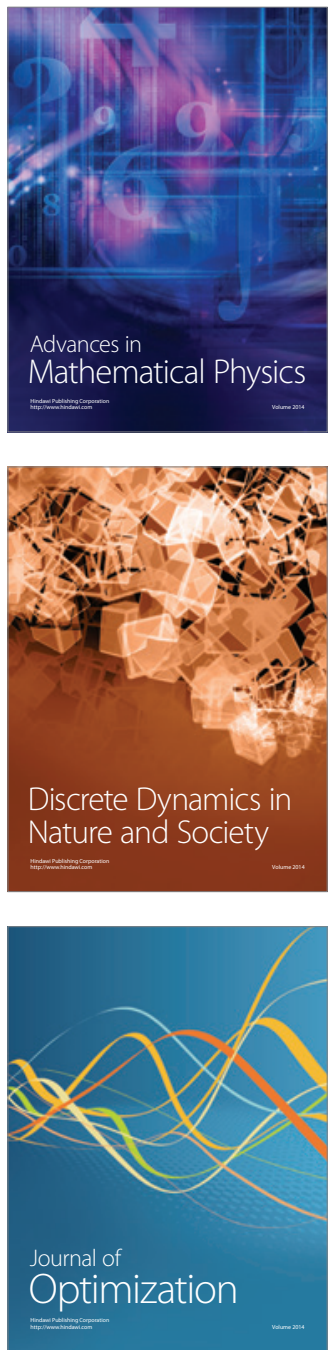